\title{
SISTEMA DE MONITORAMENTO DE PERDAS VISÍVEIS DE CANA-DE-AÇÚCAR EM COLHEDORA DE CANA PICADA
}

\author{
JORGE L. M. NEVES ${ }^{1}$, PAULO S. G. MAGALHÃES ${ }^{2}$, WALTER M. OTA ${ }^{3}$
}

\begin{abstract}
RESUMO: A área de cana colhida mecanicamente tem crescido, sobretudo em regiões com relevo até $12 \%$ de declividade, principalmente por ser essa uma forma de viabilizar a colheita de cana-de-açúcar crua a um custo competitivo. A adoção desse sistema introduz certos inconvenientes, tais como: aumento dos índices de matéria estranha na carga, o que, por sua vez, implica a redução da qualidade tecnológica da matéria-prima fornecida para moagem, e perdas de colmos e/ou frações no campo. A tentativa de reduzir tais índices, por meio do aumento da velocidade de saída de ar dos extratores das colhedoras, pode aumentar as perdas de matéria-prima em níveis inaceitáveis economicamente. Este trabalho avaliou o nível de perdas visíveis de lascas de cana, por meio do extrator primário da colhedora, para duas rotações do ventilador, monitorado por sensor de perdas de cana desenvolvido especialmente para esse fim. Em seguida, essas perdas foram relacionadas com a eficiência de limpeza da colhedora. Os resultados mostraram que a eficiência de limpeza do extrator primário (cerca de $85 \%$ ), as perdas de cana-de-açúcar em geral (entre 5,68\% e 2,51\%) e a velocidade do ventilador estão diretamente relacionados. As perdas (totais), e principalmente lascas (entre 3,91\% e 0,91\%), apontaram diferenças significativas entre os tratamentos estudados.
\end{abstract}

PALAVRAS-CHAVE: cana crua, colheita, mecanização.

\section{SUGAR CANE LOSS MONITOR, ADAPTED TO A COMMERCIAL CHOPPER SUGAR- CANE HARVESTER}

SUMMARY: In the last few years the sugar-cane mechanical harvested area has increased, especially in regions with appropriated slop. The use of this technology brings some inconveniences, such as, the increase in the percentage of extraneous matter, which causes the reduction of technological quality of the raw material, and losses in the field. Extraneous matter (trash) is composed of tops and leaves in major percentage, plus soil and roots, and eventually some metal parts. In the green cane harvest system the percentage of extraneous matter has a tendency to increase due to the great amount of vegetal matter to be processed. The increase in the blower fan speed to reduce the amount of extraneous matter can lead to an unacceptable economic level of raw material losses. The main objective of this work was, using a cane loss monitor, to evaluate and quantify the amount of visible losses of sugar cane through the primary extractor at two different fan speeds. Afterwards these losses were related to the harvester cleaning efficiency. The piezoelectric transducer shows a reasonable sensibility. The results show that the cleaning efficiency in the primary extractor ( $85 \%$ mean), the cane losses (between $5.68 \%$ and $2.15 \%$ ) and fan speed are interrelated. The total losses and specially splinters (between $3.19 \%$ and $0.91 \%$ ), showed a significant difference among the treatments.

KEYWORDS: green cane, harvesting, mechanization.

\footnotetext{
${ }^{1}$ Eng ${ }^{0}$ Mecânico, Centro de Tecnologia da Copersucar - CTC, Piracicaba - SP, Fone (0XX19) 3429.1814, e-mail: jorge-neves@ copersucar.com.br

${ }^{2}$ Eng ${ }^{0}$ Agrícola, Professor Titular, FEAGRI/UNICAMP, Campinas - SP.

${ }^{3}$ Aluno do curso de graduação em Engenharia Agrícola, FEAGRI/UNICAMP, Campinas - SP. Estagiário do CTC/Copersucar.

Recebido pelo Conselho Editorial em: 21-11-2003

Aprovado pelo Conselho Editorial em: 30-9-2004
} 


\section{INTRODUÇÃO}

A área colhida de cana-de-açúcar no Brasil cresceu de 4,56 x $10^{6}$ hectares em 1995 para 5,34 x $10^{6}$ hectares em 2003, o que corresponde a 17,2\% de incremento (BRASIL, 2004). A produtividade média da cana, após aumento de 66,6 $\mathrm{Mg} \mathrm{ha}^{-1}$ em 1995 para 69,2 $\mathrm{Mg} \mathrm{ha}^{-1}$ em 1998, apresentou uma redução para $67,8 \mathrm{Mg} \mathrm{ha}^{-1} \mathrm{em} 2000$ em função de problemas climáticos, mas voltou a crescer em 2003 chegando a 72,9 $\mathrm{Mg} \mathrm{ha}^{-1}$. A evolução da produtividade permite visualizar as dificuldades a serem enfrentadas nas zonas canavieiras menos dinâmicas, dado o desafio de substituir um complexo consolidado há séculos, por uma alternativa consistente, em termos da geração de emprego e renda (GONÇALVES \& VEIGA FILHO, 1999).

Segundo MAGALHÃES \& BRAUNBECK (1998), o setor canavieiro enfrenta problemas pela falta de tecnologia apropriada, principalmente no setor agrícola que, aliado à questão da sazonalidade da mão-de-obra, tem onerado o custo da produção o qual, sem o subsídio do Governo Federal, tem enfrentado sérios impasses financeiros. Na tentativa de reduzir custos e melhorar a rentabilidade do setor, as usinas, a exemplo do que ocorreu nas demais culturas, têm optado por um sistema gradual de mecanização, principalmente da colheita. Da área do Estado de São Paulo, segundo a ALCOBRÁS (2003), apenas $30 \%$ foram colhidos por máquinas na safra de 2003, sendo que esse percentual tende a aumentar rapidamente nos próximos anos devido a vários fatores, como custo de colheita e escassez de mão-de-obra, mas, sobretudo, em virtude do decreto do Governo do Estado $n^{\circ} 45.869$, de 22 de junho de 2001, que regulamenta a prática da queima de canaviais, e da Lei Estadual $n^{\circ} 11.241$, de 19 de setembro de 2002, que define procedimentos, proibições, estabelece regras de execução e medidas de precaução a serem obedecidas quando do emprego do fogo em práticas agrícolas, pastoris e florestais. $\mathrm{O}$ decreto estabelece, em seu artigo primeiro, que o emprego do fogo, como método de despalhe e facilitador do corte da cana-de-açúcar, deve ser eliminado de forma gradativa, não podendo a redução, a cada período de cinco anos, ser inferior a $25 \%$ da área de cada unidade agroindustrial ou propriedade não vinculada à unidade agroindustrial.

A adoção do sistema preconizado de colheita introduziu certos inconvenientes, tais como o aumento dos índices de matéria estranha na carga, o que, por sua vez, implicam a redução da qualidade tecnológica da matéria-prima fornecida para moagem e perdas de cana no campo (FERNANDES et al., 1977). Considera-se matéria estranha ao processamento industrial da cana-de-açúcar tudo que não é colmo industrializável.

Na colheita mecânica de cana crua, em que não se queima o canavial para efetuar uma prélimpeza nas canas, os índices de perdas e de matéria estranha tendem a aumentar devido à maior massa vegetal que será processada pela colhedora. As perdas de cana-de-açúcar podem ser divididas em perdas visíveis e invisíveis, em que as primeiras são aquelas que podem ser detectadas visualmente no campo após a colheita, podendo ser colmos inteiros e/ou suas frações, rebolos e tocos resultantes no corte basal, enquanto as perdas invisíveis são na forma de caldo, "serragem" e estilhaços de cana que ocorrem em razão da ação dos mecanismos rotativos que cortam, picam e limpam a cana durante o processamento interno nas colhedoras.

A tentativa de reduzir os índices de matéria estranha na cana colhida, aumentando-se a rotação dos extratores/ventiladores das colhedoras, pode elevar as perdas de matéria-prima para níveis inaceitáveis economicamente. Por outro lado, o sistema de extratores e/ou ventiladores, responsável pela maior demanda de potência disponível no motor, é o ponto principal de ocorrência de perdas de matéria-prima (YOUNGER, 1980). Segundo MORAES (1992), pelos levantamentos de dados de perdas visíveis e invisíveis na colheita por colhedoras de cana picada, obtiveram-se, em média, 10\% de perdas totais e, no extrator primário da colhedora, responsável pela limpeza, as perdas invisíveis foram da ordem de $2 \%$ em rebolos, lascas, "serragem" e caldo. 
No Centro de Tecnologia Copersucar, desenvolveu-se um programa de avaliação técnicooperacional das colhedoras de cana picada, visando à melhoria do desempenho desses equipamentos no que se refere às perdas de matéria-prima, com a instalação de monitor de perdas. O objetivo deste trabalho foi o de avaliar o nível de perdas visíveis de lasca de cana por meio do extrator primário da colhedora, trabalhando sob duas velocidades de rotações do ventilador e relacionando as perdas com a eficiência da limpeza da máquina.

\section{MATERIAL E MÉTODOS}

Os ensaios foram realizados na Usina Santa Adélia, cujas coordenadas geográficas da área de estudo são: latitude $21^{\circ} 30^{\prime} 58,85^{\prime \prime}$, longitude $48^{\circ} 17^{\prime} 31,35^{\prime \prime}$ e altitude $619,98 \mathrm{~m}$. A variedade plantada foi a RB72454, de terceiro corte, espaçamento de $1,5 \mathrm{~m}$, na safra 97/98.

O monitor de perdas fabricado pela empresa australiana Rimik foi instalado em uma colhedora Cameco CHT 2500. Consiste de um sensor piezelétrico de impacto instalado na carenagem ("capuz") de eliminação de matéria estranha do extrator primário da colhedora (Figura 1) e de um mostrador digital que apresenta a contagem de impactos captados pelo sensor.

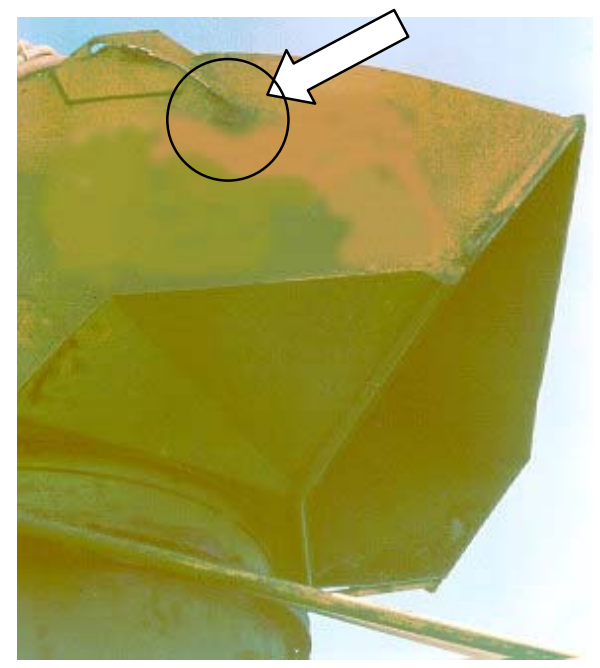

FIGURA 1. Posicionamento do sensor piezelétrico instalado no capuz da colhedora Cameco CHT 2500 .

O levantamento de perdas foi realizado em uma área demarcada onde foram recolhidas as sobras de cana-de-açúcar deixadas no campo (MFC - Massa Foliar no Campo). A área delimitada (parcela) possuía 5,6 $\mathrm{m}$ de largura (quatro fileiras) por 4,0 m de comprimento. Essas parcelas foram escolhidas aleatoriamente, sendo retiradas dez amostras para cada rotação do extrator avaliada. Nessas áreas, as perdas de cana e de palha foram coletadas e separadas de acordo com a classificação proposta:

- Tocos: fração do colmo cortada acima da superfície do solo, presa às raízes não arrancadas, com comprimento menor ou igual a $0,2 \mathrm{~m}$; comprimentos maiores são considerados pedaços.

- Cana inteira: fração de cana com tamanho igual ou superior a $2 / 3$ do comprimento médio estimado dos colmos do local. Esse colmo pode ou não estar preso ao solo, pelas raízes.

- Cana ponta: fração de colmo deixada no solo e agregada ao ponteiro. A retirada de cana ponta foi efetuada quebrando-se manualmente o colmo, no ponto de menor resistência.

- Rebolos: fração do colmo com o corte característico do facão picador ou do corte de base, em ambas as extremidades. 
- Lascas: fragmentos de cana dilacerados.

- Pedaços: todas as variações visíveis de colmos sem as características que definam tocos, colmos inteiros, rebolos, lascas e cana ponta e que, portanto, não se encaixam em nenhuma das definições anteriormente citadas.

Os componentes lascas e pedaços indicam diretamente a influência da rotação do exaustor quanto às perdas. À medida que se aumenta a rotação do exaustor primário, os rebolos passam a ser sugados junto com a palha e a terra, sendo lançados ao campo; ao passar pelos exaustores, os rebolos são atingidos pelas pás, sendo dilacerados em lascas e pedaços, contribuindo para o aumento das perdas.

Após a separação, as parcelas foram pesadas e os resultados anotados em planilhas padronizadas. Com base nos levantamentos das produtividades (obtidos na balança da usina no término da colheita) dos talhões em teste, foi possível obter as perdas visíveis de cana referentes ao extrator primário, em termos porcentuais.

A título de comparação, foi pesada, também, a quantidade de palha deixada no campo nas parcelas. Desse material, foi retirada amostra para análise de umidade, caso em que não houve separação de palha e ponteiros, como no teste de matéria estranha, mas, sim, a coleta de uma amostra composta desse material.

Após o carregamento do transbordo e antes da operação de transferência da carga para a unidade de transporte, foi retirada uma amostra de cada transbordo, com o auxílio de um tambor. Essas amostras foram coletadas em braçadas, sem distinção de material. Após a coleta, o conteúdo do tambor foi despejado sobre uma lona e separado manualmente em rebolos e matéria estranha vegetal (ponteiros + palha, deixados em separado).

O material de maior tamanho (rebolos, ponteiros, folhas verdes e folhas secas) foi separado por catação. Os pedaços de dimensões reduzidas de palha e a terra foram coletados usando-se pá e vassoura, sendo separados por meio de peneira; em seguida, o material foi classificado e pesado para cada uma das parcelas. Os materiais mais leves (palha e ponteiro) foram pesados em balança de $30 \mathrm{~N}$ de fundo de escala e o material mais pesado (rebolos), com a célula de carga de $1 \mathrm{kN}$, após o que se retirou uma pequena subamostra ( $2 \mathrm{~N}$, aproximadamente) da palha e do palmito (ponteiros) que foram picados e lacrados em sacos plásticos separados, para a determinação da umidade em laboratório, pelo método de estufa a $100{ }^{\circ} \mathrm{C}$ por 24 horas (ASAE, 1999). Tal procedimento foi necessário devido à diferença de umidade dos componentes da matéria estranha (ponteiros e palha), sendo necessário, para fins de comparação, considerá-los na mesma base (matéria seca). Após as pesagens e retirada de subamostras, o material foi devolvido aos transbordos para não alterar a carga original.

\section{Rotação do ventilador e velocidade de operação}

Foram utilizadas duas rotações do ventilador do extrator primário: $1.200 \mathrm{rpm}$, rotação geralmente empregada durante as operações de colheita, e $1.500 \mathrm{rpm}$, rotação máxima, em muitos casos empregada por acreditar-se que nessa rotação existe uma redução na porcentagem de matéria estranha na carga transportada para a usina sem aumento significativo da perda de matéria-prima. A velocidade de deslocamento foi fixada em $4 \mathrm{~km} \mathrm{~h}^{-1}$ para a colhedora, considerada faixa normal de trabalho, sendo medida por um sensor indutivo adaptado à roda motriz da esteira da colhedora.

\section{Método de calibração do monitor de perdas}

Para calibrar o monitor de perdas, zerou-se, de início, o visor do monitor e, em seguida, foram lançados rebolos de cana no extrator primário, no sentido do fluxo de palha, na velocidade máxima, ou seja, a $1.500 \mathrm{rpm}$, regulando-se o monitor por meio de uma chave reguladora até o visor registrar um valor variando de 8 a 15 perturbações. 


\section{Eficiência de limpeza de matéria estranha vegetal (Ef\%)}

A eficiência de limpeza da colhedora foi estimada tomando-se como base os resultados obtidos da matéria estranha vegetal nas amostras coletadas na cargas do veículo de transbordo (IVC, $\mathrm{Mg} \mathrm{ha}^{-1}$ ) compostas de palha (folhas verdes e secas) e ponteiros, e massa foliar remanescente no campo (MFC, $\mathrm{Mg} \mathrm{ha}^{-1}$ ) (RIPOLI, 1996).

$$
\mathrm{Ef} \%=\left(\frac{\mathrm{MFC}}{\mathrm{IVC}+\mathrm{MFC}}\right) 100
$$

Sendo a porcentagem de perdas $(\mathrm{P})$ determinada pela relação entre a massa de material coletado no campo (M) $\left(\mathrm{Mg} \mathrm{ha}^{-1}\right)$ e a produtividade média do talhão (MT) $\left(\mathrm{Mg} \mathrm{ha}^{-1}\right)$, tem-se que:

$$
\mathrm{P}=\left(\frac{\mathrm{M}}{\mathrm{M}_{\mathrm{T}}}\right) 100
$$

Todos os cálculos foram efetuados com base em peso seco, de modo a permitir a comparação entre resultados.

\section{RESULTADOS E DISCUSSÃO}

\section{Levantamento de matéria estranha}

Na Figura 2, apresentam-se os resultados das médias, em porcentagem, dos constituintes do material analisado, lascas e impurezas, na carga recebida no caminhão para colheita realizada com as rotações de 1.500 e $1.200 \mathrm{rpm}$ do ventilador do extrator primário. A análise estatística indicou que não existia diferença significativa, a 5\% de probabilidade, entre as cargas dos veículos para as componentes cana, lascas de cana e impurezas minerais; nos componentes palmito, palha e impurezas totais (base seca), os testes estatísticos indicaram diferença significativa com 95\% de confiabilidade ( $\mathrm{F}$ crítico $=4,35$ ), e a carga recolhida com a menor rotação no extrator primário apresentou maior quantidade de impurezas totais.

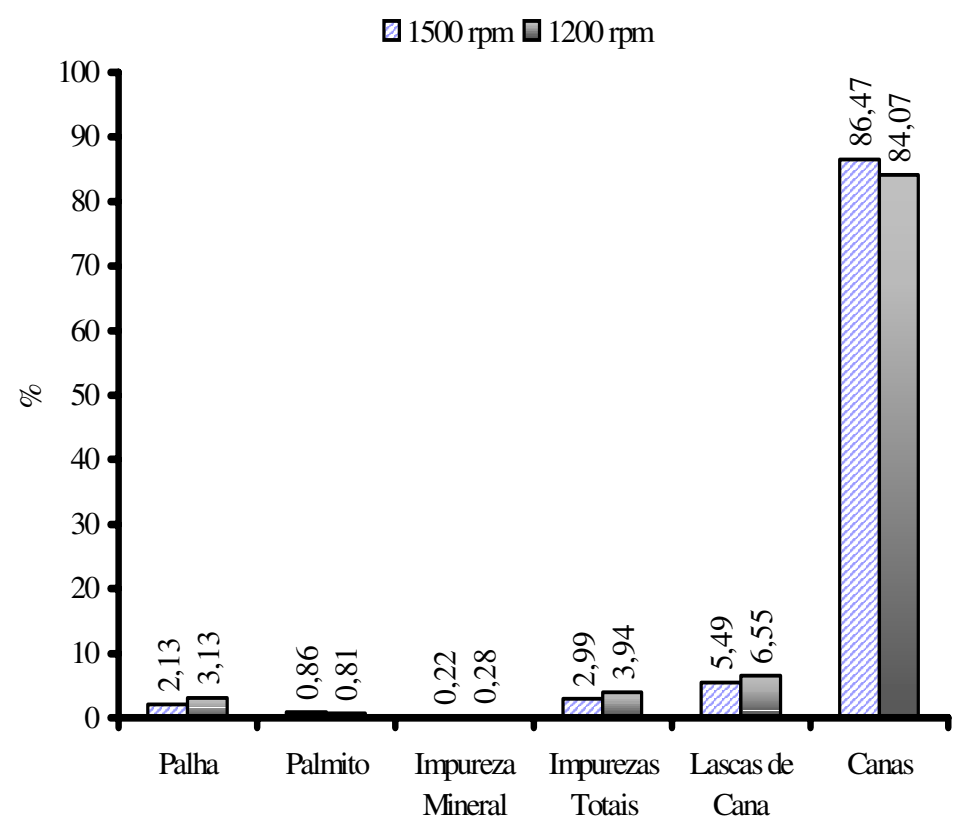

FIGURA 2. Valores médios de cana, lascas, palha, palmito, matéria estranha mineral e o total de perdas obtidos nos ensaios (\%), às rotações de 1.200 e 1.500 rpm do extrator primário. 


\section{Perda de lascas e eficiência de limpeza}

$\mathrm{Na}$ Tabela 1, encontram-se os resultados de eficiência de limpeza e a correlação com a quantidade de lascas em porcentagem e dados do visor do monitor. Para os testes conduzidos dentro da mesma faixa de velocidade de rotação do extrator primário não existem, estatisticamente, diferenças a $5 \%$ de confiabilidade; no entanto, há diferença significativa da eficiência de limpeza entre as rotações testadas a $5 \%\left(\mathrm{p}=2,1710^{-4}\right)$, sendo a eficiência de limpeza diretamente proporcional à velocidade de rotação do extrator.

TABELA 1. Valores médios das perdas e eficiência de limpeza no extrator.

\begin{tabular}{|c|c|c|c|c|c|c|c|}
\hline \multirow{3}{*}{$\begin{array}{c}\text { Rotação } \\
\text { Extrator Primário } \\
\left(\min ^{-1}\right) \\
\end{array}$} & \multicolumn{2}{|c|}{ Produtividade } & \multirow{3}{*}{$\begin{array}{c}\text { Perdas } \\
\text { (Lascas) } \\
(\%)\end{array}$} & \multicolumn{2}{|c|}{ Eficiência de Limpeza } & \multirow{2}{*}{\multicolumn{2}{|c|}{$\begin{array}{c}\text { Visor } \\
\text { Monitor de Perdas }\end{array}$}} \\
\hline & \multirow{2}{*}{$\begin{array}{c}\text { Base Úmida } \\
\left(\mathrm{Mg} \mathrm{ha}^{-1}\right)\end{array}$} & \multirow{2}{*}{$\begin{array}{l}\text { Base seca } \\
\left(\mathrm{Mg} \mathrm{ha}^{-1}\right)\end{array}$} & & \multirow{2}{*}{$\begin{array}{l}\text { Base úmida } \\
(\%)\end{array}$} & \multirow{2}{*}{$\begin{array}{c}\text { Base Seca } \\
(\%)\end{array}$} & & \\
\hline & & & & & & Variação & Média \\
\hline & & & 0 & & & & 1 \\
\hline 1.200 & 162,4 & 159,4 & 0,8 & 51,1 & 66,0 & 6 a 28 & 16 \\
\hline
\end{tabular}

Pelos valores médios apresentados na Tabela 1, observa-se que, para manter uma eficiência de limpeza na faixa de $64 \%$ e as perdas de cana em 2,6\%, o visor deve registrar um valor variando de 75 a 125 perturbações, para uma eficiência de limpeza na faixa de $51 \%$ e, para redução das perdas para $0,79 \%$, o visor deve registrar um valor variando em uma faixa de 6 a 28 perturbações.

\section{Levantamento de massa remanescente no campo (perdas)}

Na Figura 3, apresentam-se os resultados das médias dos levantamentos de rebolos, colmos inteiros, tocos, pedaços e massa foliar deixados no campo após a colheita realizada com as rotações de 1.500 e $1.200 \mathrm{rpm}$ do ventilador do extrator primário. A análise estatística indicou que as médias diferiram, significativamente, a $5 \%$ de probabilidade $(\mathrm{F}$ crítico $=4,74)$ para os valores de matériaprima total deixada no campo $\left(\mathrm{p}=1,7410^{-6}\right)$ e a massa foliar $\left(\mathrm{p}=4,2510^{-5}\right)$, sendo as perdas maiores na velocidade superior. Dentro da matéria-prima, indicou, ainda, não haver diferença (5\% de significância) entre as quantidades de colmos inteiros e tocos deixados no campo, pois esses independem da velocidade do extrator, assim como a quantidade de rebolos adequadamente cizalhados.

$$
\text { ๑ } 1500 \mathrm{rpm} \square 1200 \mathrm{rpm}
$$

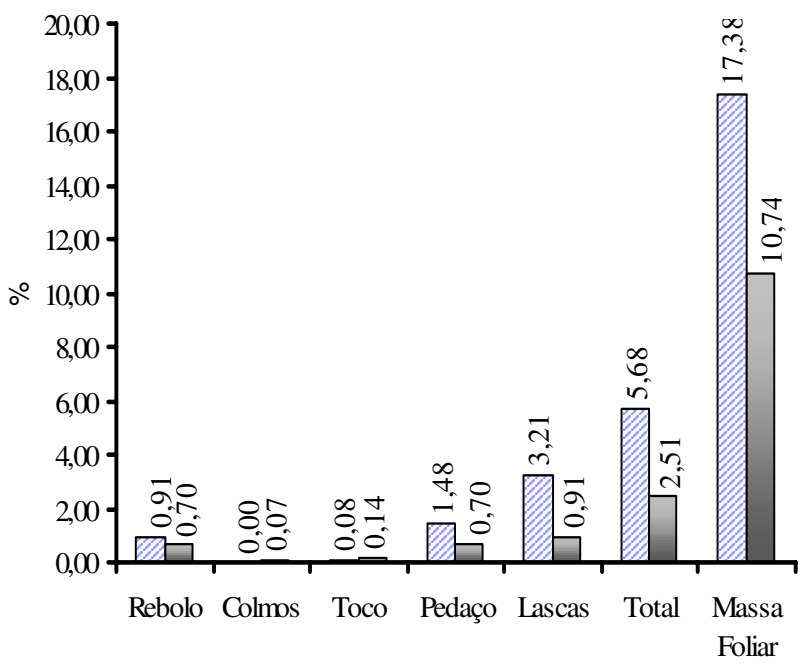

FIGURA 3. Valores médios de rebolos, colmos, tocos, pedaços, lascas, total de perdas e massa foliar deixadas no campo (\%), às rotações de 1.500 e $1.200 \mathrm{rpm}$ do ventilador do extrator primário. 


\section{CONCLUSÕES}

O uso do sensor piezelétrico apresentou boa sensibilidade aos impactos contra o capuz do extrator primário, e os valores registrados no visor do monitor de perdas permitem, ao operador da colhedora, monitorar as perdas em função da rotação do extrator primário.

A eficiência de limpeza do extrator primário, as perdas de cana-de-açúcar em geral e a velocidade de rotação do ventilador estão diretamente relacionadas, pois, quanto maior é a rotação, maior é a eficiência de limpeza e maiores são as perdas.

Os ensaios realizados mostraram diferenças significativas entre as perdas (totais) e principalmente lascas, em função da rotação do extrator primário.

A melhor eficiência de limpeza do extrator primário foi com o ventilador operando na maior rotação, considerando-se a massa vegetal tanto na base úmida como na base seca.

\section{REFERÊNCIAS}

ALCOOBRÁS. Uma safra recorde. Alcoobrás, São Paulo, n.82, p.62-4, nov-dez 2003.

AMERICAN SOCIETY OF AGRICULTURAL ENGINEERS. Moisture measurement - Forages. 46. ed. St Joseph, 1999. 569 p. (S358.2, Dec. 98)

BRASIL. Ministério da Agricultura e Abastecimento. Agricultura em números 2003. Secretaria de Política Agrícola, 2004. Disponível em:

<http://www.agricultura.gov.br.pls/portal/docs/page/mapa/estatisticas>. Acesso em: outubro 2004.

FERNANDES, A.C.; OLIVEIRA, E.R; QUEIROZ, L. Sugarcane trash measurements in Brazil. In: INTERNATIONAL SOCIETY OF SUGARCANE TECHNOLOGISTS CONGRESS, 16., 1978, São Paulo. Proceedings... São Paulo: The Executive Committee of the ISSCT Congress, 1978. v.2, p.196377.

GONÇALVES, J.S.; VEIGA FILHO, A.A. Açúcar e álcool. Disponível em: $<$ http://www.iea.sp.gov.br/dezem98.htm>. Acesso em: 18 jan. 1999.

MAGALHÃES, P.S.G.; BRAUNBECK, O.A. Colheita de cana-de-açúcar: atualidades e perspectivas In: BALBUENA, R H.; BENEZ, S.H.; JORAJÚRIA, D. Ingeniería Rural y Mecanización Agrária en el ámbito Latinoamericano. La Plata: Editora de la Universidad Nacional de La Plata, 1998. v.1, p.262-73.

MORAES, E.E. Avaliação das perdas invisíveis de cana-de-açúcar (Saccharum Spp.) e impurezas vegetais na colheita mecanizada. 1992.124 f. Dissertação (Mestrado em Máquinas Agrícolas) Faculdade de Engenharia Agrícola, Universidade Estadual de Campinas, Campinas, 1992.

RIPOLI, T.C.C. Ensaio \& certificação de máquinas para colheita de cana-de-açúcar. In: MIALHE, L.G. Máquinas agrícolas: ensaios \& certificação. Piracicaba: Fundação de Estudos "Luiz de Queiroz", 1996. cap. 13, p.635-73.

YOUNGER, J.A. Quality cane and extraneous matter. In: INTERNATIONAL SOCIETY OF SUGARCANE TECHNOLOGISTS CONGRESS, 17., 1980, Manila. Proceedings... Philippines: The Executive Commite of the ISSCT Congress, 1980. v.1, p.885-90. 